\title{
Erratum to: Serious adverse events after HPV vaccination: a critical review of randomized trials and post-marketing case series
}

\author{
Manuel Martínez-Lavín ${ }^{1,2}$ • Luis Amezcua-Guerra ${ }^{1,2}$
}

Published online: 29 July 2017

(C) International League of Associations for Rheumatology (ILAR) 2017

\section{Erratum to: Clin Rheumatol}

DOI 10.1007/s10067-017-3768-5

The original version of this article, unfortunately, contained an error.

The above article originally published with an error present in the 9-valent dose listed within the abstract. Originally reading "...For the 9-valent dose, our calculated number needed to seriously harm is $140(95 \% \mathrm{CI}, \mathbf{7 9 6 - 5 3}) \ldots "$, this should instead have read "...For the 9-valent dose, our calculated number needed to seriously harm is 140 (95\% CI, 79-653)..." [bold text used to highlight problem area].

The original article was corrected.

The online version of the original article can be found at http://dx.doi.org/ $10.1007 /$ s10067-017-3768-5

\footnotetext{
Manuel Martínez-Lavín drmartinezlavin@gmail.com

1 Rheumatology Department, National Institute of Cardiology, Juan Badiano 1, 14080 Mexico City, Mexico

2 Immunology Department, National Institute of Cardiology, Juan Badiano 1, 14080 Mexico City, Mexico
} 